\title{
RAD18 polymorphisms are associated with platinum- based chemotherapy toxicity in Chinese patients with non-small cell lung cancer
}

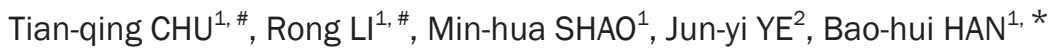 \\ ${ }^{1}$ Department of Pulmonary Medicine, Shanghai Chest Hospital, Shanghai Jiao Tong University, Shanghai 200030, China; ${ }^{2}$ Institutes of \\ Biomedical Sciences, Fudan University, Shanghai 200032, China
}

\begin{abstract}
Aim: Although targeted therapy is very efficient for lung cancer, traditional platinum-based chemotherapies are still the principal strategy in the absence of positive biomarkers. The aim of the present study is to evaluate the contribution of RAD18 polymorphisms to platinum-chemotherapy response and its potential side effects in Chinese patients with non-small cell lung cancer (NSCLC). Methods: A total of 1021 Chinese patients with histological diagnosis of advanced NSCLC were enrolled. Treatment responses were classified into 4 categories (complete response, partial response, stable disease and progressive disease). Gastrointestinal and hematological toxicity incidences were assessed twice a week during the first-line treatment. Ten RAD18 SNPs were genotyped. A logistic regression model was utilized to analyze the associations between RAD18 SNPs and treatment response or toxicity. Results: Among the 10 SNPs tested, none was significantly correlated with the treatment response in a combined cohort. For gastrointestinal toxicity incidences, rs586014 was significantly associated with an increased risk of grade 3 or 4 gastrointestinal toxicity in non-smokers and in the combined cohort; rs654448 and rs618784 were significantly associated with gastrointestinal toxicity in non-smokers; rs 6763823 was significantly associated with gastrointestinal toxicity in smokers. For hematological toxicity incidences, rs586014, rs654448 and rs618784 were significantly associated with hematologic toxicity in non-smokers; rs6763823 and rs9880051 were significantly associated with leukocytopenia in smokers.

Conclusion: RAD18 polymorphisms are correlated with the side effects of platinum-chemotherapy in Chinese patients with advanced NSCLC.
\end{abstract}

Keywords: NSCLC; platinum-based chemotherapy; RAD18 polymorphisms; gastrointestinal toxicity; hematological toxicity

Acta Pharmacologica Sinica (2016) 37: 1490-1498; doi: 10.1038/aps.2016.100; published online 26 Sep 2016

\section{Introduction}

The estimated incidence of lung cancer is second to prostate cancer and breast cancer in male and females, respectively ${ }^{[1]}$. Furthermore, lung cancer is also the leading cause of cancerrelated deaths worldwide, of which non-small cell lung cancer (NSCLC) accounts for approximately $80 \%{ }^{[2]}$. The incidence of lung cancer, especially NSCLC, has been increasing rapidly in the last two decades, due to tobacco-use, air pollution, and other cancer-related issues ${ }^{[3]}$. Previous studies have demonstrated that targeted therapy is efficient and tremendously improves the progress-free survival (PFS) and overall survival (OS) of lung cancer, especially for NSCLC adenocarcinoma ${ }^{[4-6]}$.

\footnotetext{
\# These authors contributed equally to this work.

* To whom correspondence should be addressed.

E-mail hbhxkyy@126.com

Received 2016-02-24 Accepted 2016-07-29
}

Nevertheless, traditional platinum-based chemotherapies are still the principal treatments for NSCLC patients in the absence of positive biomarkers ${ }^{[7,8]}$.

Platinum inhibits tumor growth by coupling with DNA and terminating DNA replication ${ }^{[9]}$. In this way, however, the regular reproduction of normal cells will also be suppressed, and normal and functional cells will be inevitably damaged when attempting to suppress tumors.

Previous studies have indicated that DNA repair systems participate in platinum-based chemotherapy resistance ${ }^{[9-12]}$. DNA inter- or intra-crosslinks caused by platinum chemotherapy can be removed by several DNA repair pathways, including base excision repair (BER), nucleotide excision repair (NER) and mismatch repair (MMR) ${ }^{[10]}$. Most DNA damage can be successfully repaired by the above error-free DNA repair pathways. However, when error-free DNA repair systems are stalled or saturated, these lesions can be repaired by trans- 
lesion synthesis (TLS), an error-prone DNA repair system. Error-free lesion bypass switches damaged sites to undamaged DNA strands for synthesis past the DNA lesion, while errorprone lesion bypass tolerates DNA distortions to allow synthesis past the lesion ${ }^{[13]}$. Instead of cutting the mutation base or nucleotide around the lesions and making another copy of the opposite template, the TLS pathway permits continuity of the replication fork by allowing replication through these lesions ${ }^{[14]}$. First, one of the translesion synthesis polymerases is recruited to the stalled replication fork for replication over the lesion, which is facilitated by DNA damage-induced PCNA monoubiquitination ${ }^{[15,16]}$. Second, following incorporation of a nucleotide opposite the damage site, extension polymerase replaces the TLS polymerase and further extends the patch by approximately 18 nucleotides. In this step, the damaged site escaped detection by $3^{\prime}-5^{\prime}$ exonuclease proofreading. Third, after extension past the DNA lesion, the extension polymerase is switched back to the high fidelity DNA polymerase for resuming DNA replication. Hence, TLS may be regarded as a double-edged sword because translesion synthesis polymerases have a high tendency to introduce mutations at the sites of lesions in the extension step. These mutations might lead to platinum-chemotherapy resistance ${ }^{[17-19]}$ and side effects.

RAD18 is an integral protein with a RING finger domain. Moreover, RAD18 has ubiquitin-ligating enzyme (E3) activity $^{[20]}$ and is essential for the ubiquitination of proliferating cell nuclear antigen (PCNA). Monoubiquitinated PCNA activates the TLS and recruits translesion synthesis polymerases to the DNA damaged sites ${ }^{[21]}$. Monoubiquitination of PCNA increases the affinity of translesion synthesis polymerases at damaged sites due to the presence of ubiquitin-binding domains ${ }^{[22]}$. Although PCNA polyubiquitination has also been reported in response to DNA-damaged sites, the rate is approximately 20-fold lower than PCNA monoubiquitination $^{[23]}$. Hence, RAD18 polymorphism might play a key role in the activation of TLS. A previous study demonstrated that RAD18 knocked out mouse embryonic stem cells were hypersensitive to DNA-damaging agents ${ }^{[24]}$. RAD18 participates in the maintenance of genome stability ${ }^{[25]}$. Furthermore, it has been discovered that the RAD18 polymorphism is associated with NSCLC risk ${ }^{[26]}$.

In the present study, we hypothesize that platinum-based chemotherapy can increase the global DNA damage level and TLS would be an efficient rescue pathway for both tumor and other functional cells. We used SNP to explore the contribution of the RAD18 gene to the side-effect toxicity and prognosis of platinum-based chemotherapy.

\section{Materials and methods Study population}

A total of 1021 patients who were recently histologically diagnosed with advanced NSCLC (aNSCLC) were recruited from Shanghai Chest Hospital between Mar 2005 and Jan 2010, as described in our previous study ${ }^{[27]}$. Patients who accepted at least two treatment cycles and fulfilled the following criteria were included in the study: (1) 18-80 years old; (2) stage III-IV without radical surgery; (3) no history of malignancy except non-melanoma skin cancer, in situ carcinoma of the cervix or "cured" malignant tumor (>5-year disease-free survival); (4) no chemotherapy history; (5) Eastern Cooperative Oncology Group 0-2; (6) normal liver and kidney function; (7) no uncontrolled infectious diseases, serious medical or psychological factors or active congestive heart failure; (8) no previous surgical treatment and (9) no relapse. All patients were unrelated ethnic Han Chinese. All patients consented to participate in the study and to allow their biological samples to be genetically analyzed in accordance with the process approved by the Ethical Committee of the Hospital.

Personal information, including age at diagnosis, gender, smoking status and packs per year, family and personal history of disease, was recorded from patients' self-reports. The clinical index involved in the analysis was gathered from clinical laboratory reports and pathological reports.

The patients' responses to treatment were determined by the WHO criteria, which classifies response into four categories: complete response (CR), partial response (PR), stable disease (SD) and progressive disease (PD). Term effect was assessed after two cycles of treatment. The gastrointestinal and hematological toxicity incidence was assessed twice a week during first-line treatment, according to the National Cancer Institute Common Toxicity Criteria.

\section{Chemotherapy regimen}

All patients involved in this study accepted a platinum-based chemotherapy regimen combined with other medicine. Most patients accepted one of the following treatment regimens: vinorelbine $25 \mathrm{mg} / \mathrm{m}^{2}$, d 1 and d 8 every 3 weeks in combination with cisplatin (NP) $75 \mathrm{mg} / \mathrm{m}^{2}$ or carboplatin AUC 5 (NC), both administered on d 1 , every 3 weeks; gemcitabine $1250 \mathrm{mg} / \mathrm{m}^{2}$, d 1 and d 8 every 3 weeks in combination with cisplatin (GP) $75 \mathrm{mg} / \mathrm{m}^{2}$ or carboplatin AUC 5 (GC), both administered on d 1, every 3 weeks; Taxol $175 \mathrm{mg} / \mathrm{m}^{2}, \mathrm{~d} 1$ every 3 weeks in combination with cisplatin (TP) $75 \mathrm{mg} / \mathrm{m}^{2}$ or carboplatin AUC 5 (TC), both administered on d 1, every 3 weeks; docetaxel $75 \mathrm{mg} / \mathrm{m}^{2}$, d 1 every 3 weeks in combination with cisplatin (DP) or carboplatin AUC 5 (DC) $75 \mathrm{mg} / \mathrm{m}^{2}$, also administered on $\mathrm{d} 1$, every 3 weeks. The other patients accepted different regimens with platinum-based combination therapy and other medicines. All patients maintained treatment for at least two cycles and ended up with serious resistance or side effects.

\section{Specimen preparation}

Before the patients began their treatment, $2 \mathrm{~mL}$ of peripheral blood was collected in EDTA-anticoagulant tubes. Genomic DNA was extracted from the blood, using the QIAamp DNA MAX Kit (Qiagen, Hilden, Germany), according to the manufacturer's protocol.

\section{SNP pick up and genotyping}

A total of 10 tag-SNPs were chosen. Genotype data of the RAD18 gene region (including $2 \mathrm{~kb}$ upstream) from the $\mathrm{CHB}$ 
population were downloaded from phase II the HapMap SNP database (http://www.hapmap.org/), and tag-SNPs were selected by Haploview 4.1 (http://www.broadinstitute. org/haploview), using a minor allele frequency (MAF) cutoff of 0.05 and a correlation coefficient $\left(r^{2}\right)$ threshold of 0.8 . Because there was a linkage disequilibrium (LD) in the same gene region, we believed tag-SNPs with $r^{2}>0.8$ could represent RAD18 genetic variants (Table 1). To genotype the SNPs, iPLEX chemistry on a matrix-assisted laser desorption/ionization time-of-flight mass spectrometer (Sequenom, Inc) was used.

\section{Statistical analysis}

For data analysis, CR and PR were combined as responders, and SD and PD were grouped as non-responders. Toxicity outcomes were dichotomized by the presence or absence of grade 3 or 4 toxicity during the first-line treatment.

Testing for Hardy-Weinberg equilibrium among patients was performed using observed genotype frequencies and a nonparametric $\chi^{2}$ test with one degree of freedom. SNPs with a statistical significance or marginal significance were further examined by a stratified analysis in sub-populations, which were grouped according to sex, age, smoking status or treatment regimens. A logistic regression analysis was used to estimate the odds ratio (ORs) and corresponding 95\% confidence interval ( $95 \% \mathrm{CI})$ for the associations between the genotypes with the response to treatment or severe side effects. Progression-free survival (PFS) and overall survival (OS) distributions were analyzed using the Kaplan-Meier method and the logrank test. Multivariable Cox proportional hazards regression was also used to adjust for gender, age at diagnosis, stage, histological type and smoking status. A $P$ value of $<0.05$ was

Table 1. Characteristic of the patients and genotype distribution of the selected SNPs.

\begin{tabular}{|c|c|}
\hline Patient characteristics & $n(\%)$ \\
\hline Total № patients & 1021 \\
\hline \multicolumn{2}{|l|}{ Median age in years } \\
\hline$\leq 58$ years-old & $533(52.2)$ \\
\hline$>58$ years-old & $488(47.8)$ \\
\hline \multicolumn{2}{|l|}{ Gender } \\
\hline Male & $718(70.3)$ \\
\hline Female & $303(29.7)$ \\
\hline \multicolumn{2}{|l|}{ Performance status (PS) } \\
\hline $0-1$ & $943(93.4)$ \\
\hline 2 & $67(6.6)$ \\
\hline \multicolumn{2}{|l|}{ TNM stage } \\
\hline IIIA & $81(7.9)$ \\
\hline IIIB & $249(24.4)$ \\
\hline IV & $689(67.6)$ \\
\hline \multicolumn{2}{|l|}{ Histologic type } \\
\hline Adenocarcinoma & $651(66.8)$ \\
\hline Squamous cell & $228(23.4)$ \\
\hline Adenosquamocarcinoma & $13(1.3)$ \\
\hline Others $^{\mathrm{a}}$ & $83(8.5)$ \\
\hline \multicolumn{2}{|l|}{ Chemotherapy regimens } \\
\hline NP & $205(20.1)$ \\
\hline NC & $36(3.5)$ \\
\hline GP & $198(19.4)$ \\
\hline $\mathrm{GC}$ & $48(4.7$ \\
\hline TP & $77(7.5)$ \\
\hline $\mathrm{TC}$ & $177(17.3)$ \\
\hline DP & $53(5.2)$ \\
\hline $\mathrm{DC}$ & $28(2.7)$ \\
\hline Others $^{b}$ & 199 (19.5) \\
\hline \multicolumn{2}{|l|}{ rs373572 (n=1004) } \\
\hline $\mathrm{A} / \mathrm{A}$ & $142(14.1)$ \\
\hline $\mathrm{A} / \mathrm{G}$ & $485(48.3)$ \\
\hline $\mathrm{G} / \mathrm{G}$ & 377 (37.5) \\
\hline \multicolumn{2}{|l|}{ rs615967 (n=663) } \\
\hline $\mathrm{A} / \mathrm{A}$ & $109(16.4)$ \\
\hline$A / G$ & $339(51.1)$ \\
\hline$G / G$ & $215(32.4)$ \\
\hline
\end{tabular}

\begin{tabular}{|c|c|}
\hline Patient characteristics & $n(\%)$ \\
\hline \multicolumn{2}{|l|}{ rs588232 $(n=663)$} \\
\hline $\mathrm{A} / \mathrm{A}$ & 214 (32.3) \\
\hline $\mathrm{A} / \mathrm{T}$ & $340(51.3)$ \\
\hline $\mathrm{T} / \mathrm{T}$ & 109 (16.4) \\
\hline \multicolumn{2}{|l|}{ rs586014 $(n=997)$} \\
\hline $\mathrm{A} / \mathrm{A}$ & $133(13.3)$ \\
\hline$A / G$ & $474(47.5)$ \\
\hline $\mathrm{G} / \mathrm{G}$ & $390(39.1)$ \\
\hline \multicolumn{2}{|l|}{ rs654448 $(n=663)$} \\
\hline $\mathrm{A} / \mathrm{A}$ & 257 (38.8) \\
\hline$A / G$ & $313(47.2)$ \\
\hline $\mathrm{G} / \mathrm{G}$ & $93(14.0)$ \\
\hline \multicolumn{2}{|l|}{ rs6763823 (n=985) } \\
\hline$A / A$ & $66(6.7)$ \\
\hline$A / G$ & $349(35.4)$ \\
\hline $\mathrm{G} / \mathrm{G}$ & $570(57.9)$ \\
\hline \multicolumn{2}{|l|}{ rs9880051 (n=663) } \\
\hline $\mathrm{A} / \mathrm{A}$ & $27(4.1)$ \\
\hline$A / G$ & $226(34.1)$ \\
\hline $\mathrm{G} / \mathrm{G}$ & $410(61.8)$ \\
\hline \multicolumn{2}{|l|}{ rs618784 $(n=663)$} \\
\hline $\mathrm{A} / \mathrm{A}$ & $262(39.5)$ \\
\hline$A / G$ & $312(47.1)$ \\
\hline $\mathrm{G} / \mathrm{G}$ & $89(13.4)$ \\
\hline \multicolumn{2}{|l|}{ rs686195 (n=663) } \\
\hline $\mathrm{A} / \mathrm{A}$ & $94(14.2)$ \\
\hline$A / G$ & $332(50.1)$ \\
\hline $\mathrm{G} / \mathrm{G}$ & $237(35.7)$ \\
\hline \multicolumn{2}{|l|}{ rs669906 $(n=663)$} \\
\hline $\mathrm{A} / \mathrm{A}$ & $94(14.2)$ \\
\hline$A / G$ & $332(50.1)$ \\
\hline $\mathrm{G} / \mathrm{G}$ & $237(35.7)$ \\
\hline
\end{tabular}

${ }^{a}$ Other carcinomas include mixed cell, neuroendocrine carcinoma or undifferentiated carcinoma.

${ }^{\mathrm{b}}$ Accepted other platinum-based combination therapy with other medicine. 
considered statistically significant. All analyses were performed with R 2.10.0. SHEsis ${ }^{[28,29]}$ was utilized to determine haplotype blocks and the association between haplotypes and clinical outcomes.

\section{Results}

\section{Patients Characteristics}

A total of 1021 advanced NSCLC patients were enrolled in this study. Baseline characteristics are summarized in Table 1. See the supplementary data for details.

As shown in Table 2, treatment response was evaluated in 966 patients, and $146(15.1 \%)$ were identified as responders, while $820(84.9 \%)$ were non-responders. The incidence of grade 3 or 4 gastrointestinal and homological toxicity is also listed in Table 2.

Table 2. Treatment response and severe toxicity of advanced NSCLC patients.

\begin{tabular}{ll}
\hline & $n(\%)$ \\
\hline Response $(n=966)$ & \\
$\quad$ Complete response (CR) or partial response (PR) & $146(15.1)$ \\
$\quad$ Progressive disease (PD) or stable disease (SD) & $820(84.9)$ \\
Toxicity outcomes & \\
Any grade 3 or 4 toxicity $(n=993)$ & $276(27.8)$ \\
Any grade 3 or 4 gastrointestinal toxicity $(n=972)$ & $63(6.5)$ \\
Any grade 3 or 4 hematologic toxicity $(n=972)$ & $273(28.1)$ \\
$\quad$ Anemia ( $n=915)$ & $18(2.0)$ \\
$\quad$ Agranulocytosis $(n=925)$ & $105(11.4)$ \\
$\quad$ Leukocytopenia $(n=971)$ & $151(15.6)$ \\
$\quad$ Thrombocytopenia $(n=941)$ & $43(4.6)$ \\
\hline
\end{tabular}

\section{SNP genotyping}

Ten SNPs were chosen for genotyping. Table 1 shows the genotype distributions of all SNPs. In the present study, the genotype distributions of all SNPs were consistent with the assumptions of the Hardy-Weinberg equilibrium $(P>0.05$, Supplementary Table S1). Rs686195 and rs669906 had exactly the same genotype distribution. Hence, rs669906 was omitted in the next analysis. As shown in Figure 1, with a stringent threshold, $r^{2}>0.66$, rs686195, rs373572, rs615967 and rs588232 were in high linkage disequilibrium. In addition, rs586014, rs654448 and rs618784, and rs6763823 and rs9880051 were in high linkage disequilibrium.

\section{Association with treatment response}

None of the SNPs was significantly correlated with treatment response in a combined cohort. Nevertheless, rs373572 showed a trend toward significance in smokers. Patients carrying the AA genotype of rs373572 were likely to be responders (adjusted $P=0.070$ ).

\section{Association with grade $\mathbf{3}$ or $\mathbf{4}$ toxicity}

The association between RAD18 polymorphism and side-effect

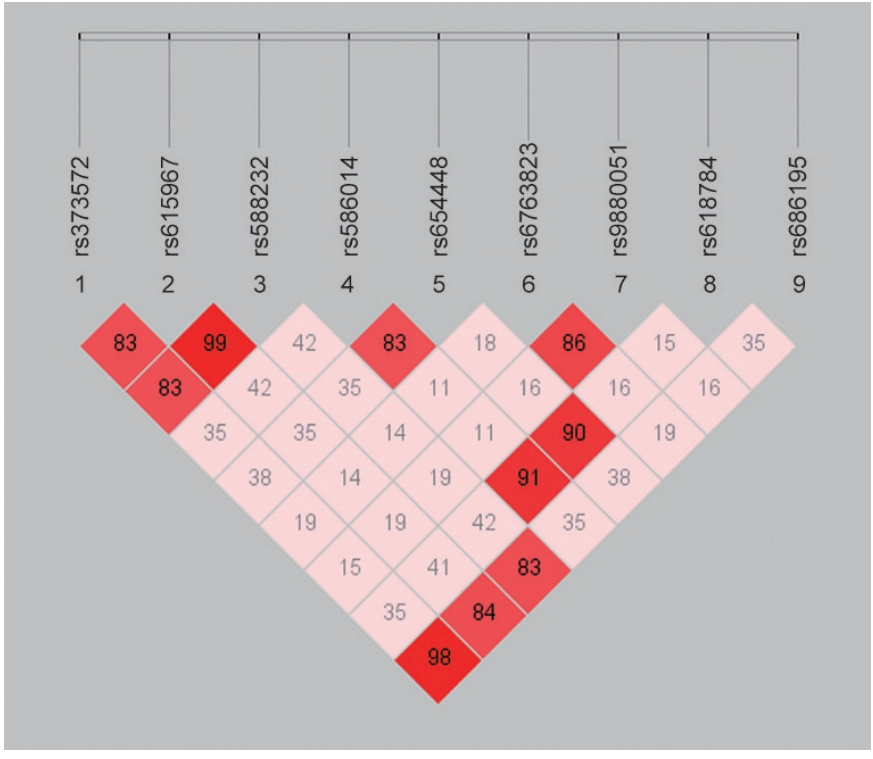

Figure 1. The linkage disequilibrium of $R A D 18$ polymorphisms in the present study. The parameter of $r^{2}>0.8$ was considered as threshold.

outcomes, including gastrointestinal and hematologic toxicity, were analyzed by logistic regression according to smoking status.

As shown in Table 3, we discovered rs586014 was significantly correlated with gastrointestinal toxicity in non-smokers and the combined cohort (adjusted $P=0.009$, OR 0.52, 95\% CI [0.31-0.85] and $P=0.003$, OR $0.40,95 \%$ CI [0.22-0.75], respectively). In addition, rs654448 and rs618784 were significantly associated with gastrointestinal toxicity in non-smokers (adjusted $P=0.018$, OR 2.75, 95\% CI [1.15-6.25] and $P=0.039$, OR 1.69, 95\% CI [1.03-2.79], respectively), while rs6763823 was significantly associated in smokers (adjusted $P=0.022$, OR 0.29 , 95\% CI [0.11-0.90]).

In the present study, we discovered three SNPs that were significantly associated with hematologic toxicity in nonsmokers, namely rs586014, rs654448, and rs618784 (Table 4). Because hematologic toxicity consisted of leukocytopenia, anemia, thrombocytopenia or agranulocytosis (Table 2), we discovered rs6763823 and rs9880051 were significantly associated with leukocytopenia in smokers $(P<0.01$, Table 5). Nevertheless, no association was found in the combined cohort for the same site.

\section{Haplotype analysis}

As mentioned above, with a stringent threshold, $r^{2}>0.66$, rs686195, rs373572, rs615967 and rs588232 were in high linkage disequilibrium and formed a haplotype block. With a $3 \%$ frequency threshold, the haplotypes were AAGA (39.0\%), GAGG $(3.3 \%)$ and GGAG (56.8\%) (in the following order: rs373572, rs615967, rs588232 and rs686195). Rs586014, rs654448 and rs618784 formed a haplotype block. With a 3\% frequency threshold, the haplotypes were AGG (34.4\%) and GAA (61.0\%) (in the following order: rs586014, rs654448 and rs618784). 


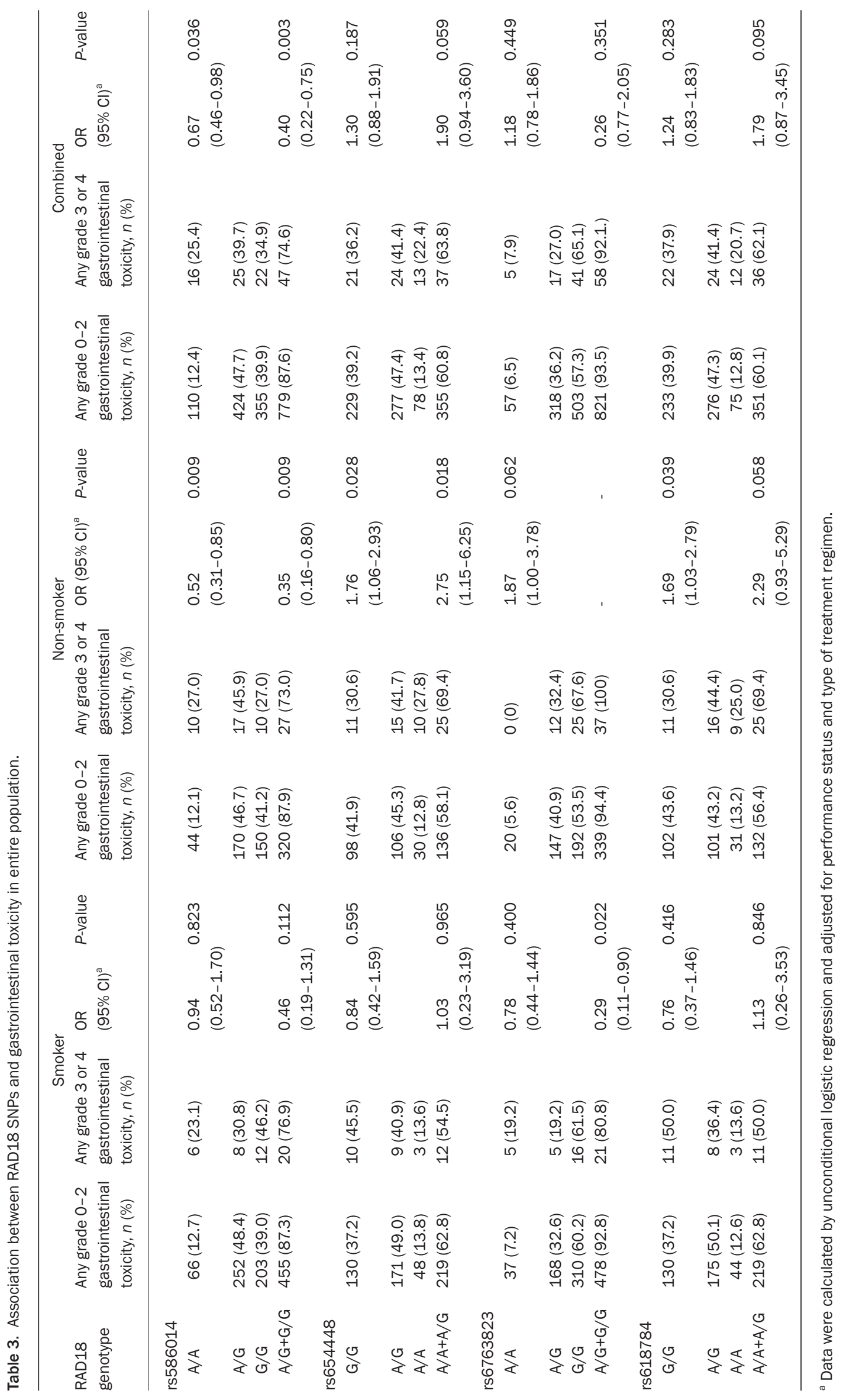


Table 4. Association between RAD18 SNPs and hematologic toxicity in non-smokers.

\begin{tabular}{|c|c|c|c|c|}
\hline RAD18 genotype & $\begin{array}{l}\text { Any grade } 0-2 \\
\text { hematologic } \\
\text { toxicity, } n(\%)\end{array}$ & $\begin{array}{l}\mathrm{N} \\
\text { Any grade } 3 \text { or } 4 \\
\text { hematologic } \\
\text { toxicity, } n(\%)\end{array}$ & OR $(95 \% \mathrm{Cl})^{\mathrm{a}}$ & $P$-value \\
\hline \multicolumn{5}{|l|}{ rs586014 } \\
\hline $\mathrm{A} / \mathrm{A}$ & $33(11.4)$ & $22(21.4)$ & $0.68(0.49-0.94)$ & 0.019 \\
\hline$A / G+G / G$ & $257(88.6)$ & $81(78.6)$ & $0.48(0.26-0.88)$ & 0.015 \\
\hline \multicolumn{5}{|l|}{ rs654448 } \\
\hline $\mathrm{G} / \mathrm{G}$ & $85(43.4)$ & $25(33.8)$ & $1.51(1.03-2.23)$ & 0.035 \\
\hline$A / G$ & $87(44.4)$ & $32(43.2)$ & & \\
\hline $\mathrm{A} / \mathrm{A}$ & $24(12.2)$ & $17(23.0)$ & & \\
\hline $\mathrm{A} / \mathrm{A}$ & $104(53.1)$ & $51(68.9)$ & & \\
\hline $\mathrm{A} / \mathrm{A}+\mathrm{A} / \mathrm{G}$ & $191(97.4)$ & $72(97.3)$ & $1.95(1.11-3.49)$ & 0.021 \\
\hline \multicolumn{5}{|l|}{ rs618784 } \\
\hline $\mathrm{G} / \mathrm{G}$ & $89(45.4)$ & $26(35.1)$ & $1.46(1.00-2.15)$ & 0.049 \\
\hline$A / G$ & $82(41.8)$ & $32(43.2)$ & & \\
\hline $\mathrm{A} / \mathrm{A}$ & $25(12.8)$ & $16(21.6)$ & & \\
\hline $\mathrm{A} / \mathrm{A}+\mathrm{A} / \mathrm{G}$ & $107(54.6)$ & $48(64.9)$ & $1.88(0.92-3.77)$ & 0.079 \\
\hline
\end{tabular}

${ }^{a}$ Data were calculated by unconditional logistic regression and adjusted for performance status and type of treatment regimen.

Table 5. Association between RAD18 SNPs and leukocytopenia toxicity in smokers.

\begin{tabular}{|c|c|c|c|c|}
\hline \multirow[b]{2}{*}{ RAD18 genotype } & \multicolumn{4}{|c|}{ Smoker } \\
\hline & $\begin{array}{l}\text { Any grade } 0-2 \\
\text { leukocytopenia } \\
\text { toxicity, } n(\%)\end{array}$ & $\begin{array}{l}\text { Any grade } 3 \text { or } 4 \\
\text { leukocytopenia } \\
\text { toxicity, } n(\%)\end{array}$ & OR $(95 \% \mathrm{Cl})^{\mathrm{a}}$ & $P$-value \\
\hline \multicolumn{5}{|l|}{ rs6763823 } \\
\hline $\mathrm{G} / \mathrm{G}$ & $293(62.5)$ & $41(50.6)$ & $0.77(0.54-1.10)$ & 0.147 \\
\hline $\mathrm{A} / \mathrm{A}+\mathrm{A} / \mathrm{G}$ & $176(37.5)$ & $40(49.4)$ & $0.60(0.38-0.95)$ & 0.031 \\
\hline \multicolumn{5}{|l|}{ rs9880051 } \\
\hline $\mathrm{G} / \mathrm{G}$ & $16(5.0)$ & $4(7.1)$ & $0.54(0.35-0.84)$ & 0.006 \\
\hline$A / G$ & $84(26.2)$ & $26(46.4)$ & & \\
\hline $\mathrm{A} / \mathrm{A}$ & $221(68.8)$ & $26(46.4)$ & & \\
\hline
\end{tabular}

${ }^{a}$ Data were calculated by unconditional logistic regression and adjusted for performance status and type of treatment regimen.

Rs6763823 and rs9880051 formed a haplotype block. With a $3 \%$ frequency threshold, the haplotypes were AA (20.9\%) and GG (76.7\%) (in the following order: rs6763823 and rs9880051).

There was no significant association between any haplotype and treatment response in the combined cohort or the subgroups, which were grouped by smoking status $(P>0.05)$.

There was no significant association between any haplotypes and gastrointestinal toxicity in the combined cohort $(P>0.05)$.
However, the AGG haplotype of rs586014-rs654448-rs618784 had an increased risk of gastrointestinal toxicity in nonsmokers $\left(P=0.018\right.$ and $P_{\text {sim }}=0.056$ after 10000 times permutation), while GAA showed the opposite effect of AGG $(P=0.018$ and $P_{\text {sim }}=0.056$ after 10000 times permutation).

There was no significant association between any haplotypes and hematologic toxicity in the combined cohort $(P>0.05)$. Nevertheless, the AGG haplotype of rs586014-rs654448- 
rs618784 had an increased risk of hematologic toxicity in nonsmokers $\left(P=0.023\right.$ and $P_{\text {sim }}=0.028$ after 10000 times permutation), while GAA showed the opposite effect of AGG ( $P=0.023$ and $P_{\text {sim }}=0.028$ after 10000 times permutation).

\section{Association with progression-free survival (PFS) or overall survival (OS)}

Utilizing the multivariable Cox proportional hazards model, we analyzed the relationship between RAD18 polymorphism and PFS or OS. However, none of the SNPs was found to be associated with PFS or OS.

\section{Discussion}

In the present study, we investigated the potential association between $R A D 18$ polymorphisms, treatment responses and the increased toxicity of platinum-based chemotherapy treatment for NSCLC. An allele of rs586014 was significantly associated with an increased risk of grade 3 or 4 gastrointestinal toxicity in non-smokers and in the combined cohort. Moreover, rs654448 and rs618784 were significantly associated with gastrointestinal toxicity in non-smokers, while rs6763823 was significantly associated with gastrointestinal toxicity in smokers. We also discovered three SNPs that were significantly associated with hematologic toxicity in non-smokers. Furthermore, rs6763823 and rs9880051 were significantly associated with leukocytopenia in smokers. We found that the AGG haplotype of rs586014-rs654448-rs618784 had an increased risk of gastrointestinal and hematologic toxicity in nonsmokers.

Although many studies have demonstrated the relationship between $R A D 18$ and cancer development ${ }^{[26,30-32]}$, this is the first known study to focus on the relationship between RAD18 polymorphism and platinum-based chemotherapy response or severe toxicity in NSCLC patients. RAD18 is a singlestrand DNA binding protein that forms a complex with RAD6 and is essential for carrying out $\mathrm{TLS}^{[33]}$. Compared with other repair pathways, TLS has a high tendency to introduce incorrect bases during translesion DNA synthesis. For example, a previous study demonstrated that RAD18 might accumulate at blocked replication forks and initiate the signal to recruit Pol $\mathfrak{l}^{[34]}$. Pol $\iota$ has a very low accuracy in DNA synthesis and tends to incorporate $\mathrm{G}$ or $\mathrm{T}$ opposite template $\mathrm{T}$ during DNA synthesis ${ }^{[35]}$. Such low fidelity translesion DNA synthesis might increase spontaneous mutagenesis, therefore resulting in platinum-chemotherapy tolerance and toxicity within normal cells.

Previous studies have demonstrated that rs 373572 is associated with the risk of NSCLS and colorectal cancer ${ }^{[26,31,36]}$. Moreover, rs373572 was found to be a unique SNP located in the coding-region of RAD18 in the present study. RAD18 has several functional domains, including RING-finger motif ${ }^{[37]}$, zinc-finger motif ${ }^{[38]}$ and E3 ubiquitin-ligase domain ${ }^{[39]}$. Because rs373572 is located in the E3 ubiquitin-ligase domain, it might affect the E3 ubiquitin-ligase activity of RAD18 and further influence the ubiquitination of PCNA and activation of TLS.

A previous study found a significantly higher RAD18 expression level in esophageal carcinomas ${ }^{[40]}$. Another recent study indicated that RAD18 overexpression might confer resistance to ionizing radiation in human glioma cells ${ }^{[41]}$. In the present study, we discovered that rs586014 was remarkably correlated with gastrointestinal and hematologic toxicity in non-smokers $(P<0.01)$. Considering that rs586014 is located within $2 \mathrm{~kb}$ upstream of $R A D 18$, the potential impact of rs586014 on the expression level of RAD18 and the side effects of platinum-base chemotherapy may be an interesting study direction.

Rs6763823 and rs9880051 were located in the intron region of RAD18. Although the association between these two SNPs and leukocytopenia toxicity in smokers was significant, additional studies are needed to confirm this finding because the number of patients with leukocytopenia in this study was small.

Considering RAD18 is essential in the activation of PCNA ${ }^{[21]}$, RAD18 polymorphism might exhibit an epistasis effect in the TLS pathway rather than a direct influence. Additionally, we discovered that the most significant associations with toxicities were observed in non-smokers. We speculated that smoking might result in somatic mutations in translesion polymerases, such as POLK and POLI, and further conceal the association between RAD18 and chemotherapy resistance and side effects in smokers. Ultimately, all of the polymorphisms in the present study were non-functional sites; therefore, the mechanism by which they influence RAD18 remains unknown. Some polymorphisms might be linked with gain of function sites, while the others might be linked with loss of function sites, which might be the reason why different polymorphisms had different effects relative to smoking status. Nevertheless, further study is required to confirm our hypothesis.

Platinum compounds, including cisplatin and carboplatin, are widely utilized in the treatment of tumors ${ }^{[42]}$. Platinum compounds react with DNA and lead to DNA lesions, including intrastrand crosslinks (Pt-d[CpG], Pt-d [ApG] and Pt-d [GpNgG]), interstrand crosslinks and single nucleotide damage involving guanine ${ }^{[43]}$. Hence, TLS that allows bypass of the intrastrand crosslinks and constitutes a critical initial step in interstrand crosslink repair ${ }^{[44]}$ is advantageous to tumor cells' survival ${ }^{[45-48]}$. These crosslink bypasses can result in resistance against platinum-based chemotherapy ${ }^{[47,49]}$. TLS plays a similar role in normal cells in the face of damaging lesions and influences the side effects of platinum-based compounds.

In summary, we discovered several RAD18 SNPs that were associated with platinum-based chemotherapy toxicity. The present study provides reference for the future study of platinum-based chemotherapy response and severe toxicity. However, due to the limitations of the present study, further in vivo functional studies are needed to elucidate the biological basis of these findings.

\section{Acknowledgements}

This work was supported by the National Natural Science Foundation of China (Grant № 81302004), Shanghai Jiao Tong University Grant for Interdisciplinary Research on Medicine and Engineering (Grant No YG2013MS12), the Major and 
Key Program of Technology Development Foundation of Shanghai Chest Hospital (Grant No 2014YZDC10101), the Program of Study Foundation of Chinese Society of Clinical Oncology(CSCO) (Grant No Y-S2015-007), and the Western Medicine Guide Project of Shanghai Committee of Science and Technology Foundation (Grant № 16411964700).

\section{Author contribution}

Prof Bao-hui HAN and Min-hua SHAO designed the research; Tian-qing CHU performed the research; Rong LI analyzed the data; Tian-qing CHU, Rong LI and Jun-yi YE wrote the paper.

\section{References}

1 Siegel R, Naishadham D, Jemal A. Cancer statistics, 2013. CA Cancer J Clin 2013; 63: 11-30.

2 Mountain CF. Revisions in the International System for Staging Lung Cancer. Chest 1997; 111: 1710-7.

3 Torre LA, Bray F, Siegel RL, Ferlay J, Lortet-Tieulent J, Jemal A. Global cancer statistics, 2012. CA Cancer J Clin 2015; 65: 87-108.

4 Pao W, Miller V, Zakowski M, Doherty J, Politi K, Sarkaria I, et al. EGF receptor gene mutations are common in lung cancers from "never smokers" and are associated with sensitivity of tumors to gefitinib and erlotinib. Proc Natl Acad Sci U S A 2004; 101: 13306-11.

5 Lynch TJ, Bell DW, Sordella R, Gurubhagavatula S, Okimoto RA, Brannigan BW, et al. Activating mutations in the epidermal growth factor receptor underlying responsiveness of non-small-cell lung cancer to gefitinib. N Engl J Med 2004; 350: 2129-39.

6 Jordan MA, Wilson L. Microtubules as a target for anticancer drugs. Nat Rev Cancer 2004; 4: 253-65.

7 Quoix E, Zalcman G, Oster JP, Westeel V, Pichon E, Lavolé A, et al. Carboplatin and weekly paclitaxel doublet chemotherapy compared with monotherapy in elderly patients with advanced non-small-cell lung cancer: IFCT-0501 randomised, phase 3 trial. Lancet 2011; 378: 1079-88.

8 Lara PN, Douillard JY, Nakagawa K, von Pawel J, McKeage MJ, Albert I, et al. Randomized phase III placebo-controlled trial of carboplatin and paclitaxel with or without the vascular disrupting agent vadimezan (ASA404) in advanced non-small-cell lung cancer. J Clin Oncol 2011; 29: 2965-71.

9 Rabik CA, Dolan ME. Molecular mechanisms of resistance and toxicity associated with platinating agents. Cancer Treat Rev 2007; 33: 9-23.

10 Martin LP, Hamilton TC, Schilder RJ. Platinum resistance: the role of DNA repair pathways. Clin Cancer Res 2008; 14: 1291-5.

11 Olaussen KA, Dunant A, Fouret P, Brambilla E, André F, Haddad V, et al. DNA repair by ERCC1 in non-small-cell lung cancer and cisplatinbased adjuvant chemotherapy. N Engl J Med 2006; 355: 983-91.

12 Gurubhagavatula S, Liu G, Park S, Zhou W, Su L, Wain JC, et al. XPD and XRCC1 genetic polymorphisms are prognostic factors in advanced non-small-cell lung cancer patients treated with platinum chemotherapy. J Clin Oncol 2004; 22: 2594-601.

13 Lindahl T, Barnes DE. Repair of endogenous DNA damage. Cold Spring Harb Symp Quant Biol 2000; 65: 127-33.

14 Waters LS, Minesinger BK, Wiltrout ME, D'Souza S, Woodruff RV, Walker GC. Eukaryotic translesion polymerases and their roles and regulation in DNA damage tolerance. Microbiol Mol Biol Rev 2009; 73: 134-54.

15 Bomar MG, Pai MT, Tzeng SR, Li SS, Zhou P. Structure of the ubiquitin-binding zinc finger domain of human DNA Y-polymerase eta.
EMBO Rep 2007; 8: 247-51.

16 Cui G, Benirschke RC, Tuan HF, Juranić N, Macura S, Botuyan MV, et al. Structural basis of ubiquitin recognition by translesion synthesis DNA polymerase I. Biochemistry 2010; 49: 10198-207.

17 Wojtaszek J, Liu J, D'Souza S, Wang S, Xue Y, Walker GC, et al. Multifaceted recognition of vertebrate Rev1 by translesion polymerases $\zeta$ and K. J Biol Chem 2012; 287: 26400-8.

18 Ceppi P, Novello S, Cambieri A, Longo M, Monica V, Lo lacono M, et al. Polymerase eta mRNA expression predicts survival of non-small cell lung cancer patients treated with platinum-based chemotherapy. Clin Cancer Res 2009; 15: 1039-45.

19 Nojima K, Hochegger H, Saberi A, Fukushima T, Kikuchi K, Yoshimura $\mathrm{M}$, et al. Multiple repair pathways mediate tolerance to chemotherapeutic cross-linking agents in vertebrate cells. Cancer Res 2005; 65: 11704-11.

20 Joazeiro CA, Weissman AM. RING finger proteins: mediators of ubiquitin ligase activity. Cell 2000; 102: 549-52.

21 Huang J, Huen MS, Kim H, Leung CC, Glover JN, Yu X, et al. RAD18 transmits DNA damage signalling to elicit homologous recombination repair. Nat Cell Biol 2009; 11: 592-603.

22 Ulrich HD. The RAD6 pathway: control of DNA damage bypass and mutagenesis by ubiquitin and SUMO. Chembiochem 2005; 6: 173543.

23 Lehmann AR, Niimi A, Ogi T, Brown S, Sabbioneda S, Wing JF, et al. Translesion synthesis: Y-family polymerases and the polymerase switch. DNA Repair (Amst) 2007; 6: 891-9.

24 Tateishi S, Niwa H, Miyazaki J, Fujimoto S, Inoue H, Yamaizumi M. Enhanced genomic instability and defective postreplication repair in RAD18 knockout mouse embryonic stem cells. Mol Cell Biol 2003; 23: 474-81.

25 Shekhar MP, Lyakhovich A, Visscher DW, Heng H, Kondrat N. Rad6 overexpression induces multinucleation, centrosome amplification, abnormal mitosis, aneuploidy, and transformation. Cancer Res 2002; 62: 2115-24.

26 Kanzaki H, Ouchida M, Hanafusa H, Yamamoto H, Suzuki H, Yano M, et al. The association between RAD18 Arg302GIn polymorphism and the risk of human non-small-cell lung cancer. J Cancer Res Clin Oncol 2008; 134: 211-7.

27 Shao M, Jin B, Niu Y, Ye J, Lu D, Han B. Association of POLK polymorphisms with platinum-based chemotherapy response and severe toxicity in non-small cell lung cancer patients. Cell Biochem Biophys 2014; 70: 1227-37.

28 Li Z, Zhang Z, He Z, Tang W, Li T, Zeng Z, et al. A partition-ligationcombination-subdivision EM algorithm for haplotype inference with multiallelic markers: update of the SHEsis (http://analysis.bio-x.cn). Cell Res 2009; 19: 519-23.

29 Shi YY, He L. SHEsis, a powerful software platform for analyses of linkage disequilibrium, haplotype construction, and genetic association at polymorphism loci. Cell Res 2005; 15: 97-8.

30 Friedberg EC. DNA damage and repair. Nature 2003; 421: 436-40.

31 Kanzaki H, Ouchida M, Hanafusa H, Sakai A, Yamamoto H, Suzuki H, et al. Single nucleotide polymorphism in the RAD18 gene and risk of colorectal cancer in the Japanese population. Oncol Rep 2007; 18: 1171-5.

32 Wong RP, Aguissa-Touré AH, Wani AA, Khosravi S, Martinka M, Martinka M, et al. Elevated expression of Rad18 regulates melanoma cell proliferation. Pigment Cell Melanoma Res 2012; 25: 213-8.

33 Watanabe K, Tateishi S, Kawasuji M, Tsurimoto T, Inoue H, Yamaizumi M. Rad18 guides poleta to replication stalling sites through physical interaction and PCNA monoubiquitination. EMBO J 2004; 23: 388696. 
34 Kakar S, Watson NB, McGregor WG. RAD18 signals DNA polymerase IOTA to stalled replication forks in cells entering S-phase with DNA damage. Adv Exp Med Biol 2008; 614: 137-43.

35 Zhang Y, Yuan F, Wu X, Wang Z. Preferential incorporation of G opposite template $\mathrm{T}$ by the low-fidelity human DNA polymerase iota. Mol Cell Biol 2000; 20: 7099-108.

36 Pan J, Chi P, Lu X, Xu Z. Genetic polymorphisms in translesion synthesis genes are associated with colorectal cancer risk and metastasis in Han Chinese. Gene 2012; 504: 151-5.

37 Costa S, Pinto D, Pereira D, Rodrigues H, Cameselle-Teijeiro J, Medeiros $\mathrm{R}$, et al. DNA repair polymorphisms might contribute differentially on familial and sporadic breast cancer susceptibility: a study on a Portuguese population. Breast Cancer Res Treat 2007; 103: 209-17.

38 Mackay JP, Crossley M. Zinc fingers are sticking together. Trends Biochem Sci 1998; 23: 1-4.

39 Marchler-Bauer A, Anderson JB, Cherukuri PF, DeWeese-Scott C, Geer LY, Gwadz M, et al. CDD: a Conserved Domain Database for protein classification. Nucleic Acids Res 2005; 33: D192-6.

40 Zhou J, Zhang S, Xie L, Liu P, Xie F, Wu J, et al. Overexpression of DNA polymerase iota (Polı) in esophageal squamous cell carcinoma. Cancer Sci 2012; 103: 1574-9.

41 Xie C, Wang H, Cheng H, Li J, Wang Z, Yue W. RAD18 mediates resistance to ionizing radiation in human glioma cells. Biochem Biophys Res Commun 2014; 445: 263-8.

$42 \mathrm{Kemp} \mathrm{Z,} \mathrm{Ledermann} \mathrm{J.} \mathrm{Update} \mathrm{on} \mathrm{first-line} \mathrm{treatment} \mathrm{of} \mathrm{advanced}$ ovarian carcinoma. Int J Womens Health 2013; 5: 45-51.

43 Fichtinger-Schepman AM, van der Veer JL, den Hartog JH, Lohman $\mathrm{PH}$, Reedijk J. Adducts of the antitumor drug cis-diamminedichloroplatinum (II) with DNA: formation, identification, and quantitation. Biochemistry 1985; 24: 707-13.

44 Haynes B, Saadat N, Myung B, Shekhar MP. Crosstalk between translesion synthesis, Fanconi anemia network, and homologous recombination repair pathways in interstrand DNA crosslink repair and development of chemoresistance. Mutat Res Rev Mutat Res 2015; 763: 258-66.

45 Salehan MR, Morse HR. DNA damage repair and tolerance: a role in chemotherapeutic drug resistance. Br J Biomed Sci 2013; 70: 31-40.

46 Zhao Y, Biertümpfel C, Gregory MT, Hua YJ, Hanaoka F, Yang W. Structural basis of human DNA polymerase $\eta$-mediated chemoresistance to cisplatin. Proc Natl Acad Sci U S A 2012; 109: 7269-74.

47 Levine RL, Miller H, Grollman A, Ohashi E, Ohmori H, Masutani C, et al. Translesion DNA synthesis catalyzed by human pol eta and pol kappa across 1,N6-ethenodeoxyadenosine. J Biol Chem 2001; 276 : 18717-21.

48 Chen YW, Cleaver JE, Hatahet Z, Honkanen RE, Chang JY, Yen Y, et al. Human DNA polymerase eta activity and translocation is regulated by phosphorylation. Proc Natl Acad Sci U S A 2008; 105: 16578-83.

49 Chen YW, Cleaver JE, Hanaoka F, Chang CF, Chou KM. A novel role of DNA polymerase eta in modulating cellular sensitivity to chemotherapeutic agents. Mol Cancer Res 2006; 4: 257-65. 